\title{
A Study on Attitude and Behavior of Rural Consumers
}

\author{
Dr. Prabhakar Shukla, Manju Sharma \\ Professor, Research Scholar \\ Department of Economics, SBM \\ Noida International University, \\ Gr. Noida, G.B. Nagar, U.P. \\ Email ID: bipincyberplaza@gmail.com
}

\begin{abstract}
It is relatively easy to measure what rural consumers buy, where they buy from and how much they buy. Understanding why they buy is the most difficult in rural India and what factors induce them to buy. This study tries to analyze the attitude and buying behavior of the rural consumers. The factors such as family size, product packaging, age, culture, and advertising have an effect on consumers decision making process, where as price is associated to product. Rural consumers are fundamentally different from their urban counterparts. The lower levels of literacy and limited exposure to product and services are well-known, but there are also differences in consumption patterns with a direct impact on income levels and income flows, and a high level of inter-dependency affecting the dynamics of rural consumer behavior. All contribute to make rural consumer behavior dissimilar from the urban consumer.
\end{abstract}

Keywords: Rural Consumer, Rural Consumer Behavior and Attitude, Indian Economy, Globalization.

\section{INTRODUCTION}

The rural consumers in India are generally ignorant and they are also unorganized. Thus, they are exploited by the manufacturers, traders and the service providers in different way. The rural consumers are not only scattered but also diverse and heterogeneous. As a result of globalization and liberalization the rural market in India is the largest potential market in the world. Thus, there are vast opportunities for rural marketing. The manufacturers and traders take advantage of the condition of the rural consumers. It has been observed that the condition of the rural consumers is deplorable because they are largely exploited in the rural markets on account of lack of competition among the sellers. The rural consumers face various problems like adulteration, short weighing and measuring, lack of safety and quality control in appliances and equipment's, electrical and mechanical, unfair warranties and guarantees, imitation, sales gimmicks and unreasonable pricing.

Rural markets in India have assumed significance in the recent past with the growth of the Indian economy. More income \& employment opportunities in rural areas have increased the purchasing power of rural consumers. Rural reach is on the rise and it is fast becoming the most important route to growth for the Industry. New approaches, new strategic alternatives and new operational techniques are being evolved to gain competitive advantage. Rural markets hitherto, found unattractive have become the new targets to corporate enterprises, mainly for two reasons. Urban market has become congested with too many competitors. Also markets have reached a near saturation point. Rural markets have become the main street with potential for consumption variety of products and services. For many a product rural market provides a promise owing to lag in adaptation. It makes market entry easy. Large population raising prosperity, growth in consumption, life style changes and life cycle advantages market growth rates higher than urban and inexpensive strategies are the various factors which have made rural market viable.

\section{BUYING BEHAVIOR AND SPENDING PATTERN OF THE RURAL CONSUMERS}

Consumer behavior in rural marketing is a behavior which is exhibited by people in planning, purchasing and using of economic goods and services. Now-adays the consumers' tastes and preferences have changed their lifestyle. The change in lifestyle of rural households is affecting their consumption patterns bringing a noticeable change in their living standard. The lifestyle changes can be seen with respect to food consumption, fashion trends, entertainment and use of technology. The Indian market has seen a tremendous change in lifestyle of a common man. The remarkable change in urban lifestyle has trickled across the rural population too. Island of poverty still exists but most of the rural area has transformed beyond imagination. A few decades ago rural consumer was a silent person who uncomplainingly purchased the goods. But this is not so today. Now the consumer is choice empowered. The companies of late have started recognizing the potential of the rural market. The changing lifestyle, higher education, better per capita income of the rural consumers and high growth rate of the rural economy has forced the companies to redesign their marketing strategies. They have started 
focusing on the changing tastes and demand of the new modern rural consumers.

This change in consumption pattern is observed due to enhanced awareness, expansion of information technology, changes in consumer taste, preference and income at micro level, structural shift in the overall environment at macro level and more importantly governmental intervention through legislations. It ultimately affects the buying behavior of consumers. The research study indicates that the rural consumers are becoming quality conscious in their food consumption, like dining outside and preference for fast food, readymade items is increasing as it reflects affluence and saves women's time. In fashion, they are opting for branded outfits and latest fashion trends which further reinforce the affluence of rural consumers. A higher trend of outings and visits to restaurant and movie halls is visible. Media, especially television has a major role in this emerging consumption pattern.

\section{RURAL CONSUMER: CHANGE IN MINDSETS}

The rural consumers are having the mindset which is taking turn towards comfortable and stylish life-style conditioned with utility and economy based behavior. They exhibit certain behavior unique to rural settings and this makes it important for marketers to understand rural consumers through appropriate research. They have greater trust in products and services endorsed by the government and its agencies. They are more brand loyal, as habits once formed are difficult to change and they tend to feel a sense of pride in getting a good deal rather than paying premium prices for products and services. That's why while formulating framework for rural markets, marketers should focus around: plugging the segments with the right product, using value for money pricing, selecting the most appropriate channel of distribution, building long term relationships with the customers.

On the basis of researches done in this field, the followings are the findings:

1. The rural consumer may not be very educated, but he is certainly astute, with a lot of common sense and practical experience of handling the vagaries and uncertainties of life. He displays great ingenuity and adaptability as evidenced by his learning to repair his tractor, hand pump and motorbike, and finding a host of local solutions in everyday life.

2. Though low on economic resources, he does not go in for only 'cheap' products but looks for value for money. Perception of a premium product is not yet relevant in rural markets, with consumers more concerned with functionality than unnecessary 'frills' with a consumer durable. Too many features with a product tend to confuse the rural consumer.

3. Rural consumers are generally mistrustful and wary of urbanities and turned off by their patronizing attitudes. It is not easy for a rank outsider to get the rural consumer to spend money.

4. Brand adherence is high among village consumers. This may not necessarily be on account of loyalties. Limited access to alternatives and lack of information about possible choices do make them 'stick' to tried and tested brands.

5. Brand recognition is often on the basis of logos, symbols, colors rather than the exact brand name. This tendency is partly responsible for the widespread menace of spurious products in rural markets, as it is easy to deceive the rural consumer with look-alikes.

6. A very high degree of involvement characterizes purchase of expensive products like consumer durables. A lot of checking and counterchecking is done to seek reassurance on the soundness of the buying decision. Marketers must embody reassurance and provide opportunity to 'see and touch' the product in their marketing communication processes.

7. Routine is important to a rural consumer's life as a lot of time consuming activities characterize his everyday life. The routine is governed by nature and seasons, not by the calendar or the clock. Sunday is not typically a holiday. In buying processes, the consumer is not in a hurry and cannot be pushed into a hasty purchase for these segments.

8. Rural incomes show a great seasonality for the segment of large farmers. The segment of petty farmers, farm labor, non-farm workers and the salaried class show a greater regularity of income patterns so the consumption cycles are also more regular and predictable.

9. On account of far higher degree of inter personal communication characterizing village life and relatively low penetration of mass media, word of mouth is a very effective medium of influence generation. Existing users, dealers, village influential, youth studying or working in urban locations are all consulted before making purchases.

10. Among the households with TV ownership, TV viewing is the highest among women and children who in contrast to the traditional, household head dominated decision scenario are fast emerging as demand generators for the household goods. Decisions on durables like radio, TV and two wheelers are still male 
dominated decisions, taken in consultation with other people in the community.

11. The rural youth are increasingly becoming more exposed to urban lifestyles on account of their frequent visits to urban locations either for higher education or for work. Their media exposure to television is also much higher. This makes urban lifestyles an inspirational model for them and their preference for national brands is on the rise.

12. While culture and social norms have a greater hold on rural consumer than urban ones, perceptions, traditions and values vary from state to state, sometimes from region to region. It is, therefore, difficult to work with a pan rural Indian communication package. Two step flow of communication, using opinion leaders and mass media both, seems to work better in rural settings. These observations made on the basis of a host of research based inputs make it very clear that rural marketing effort cannot be visualized as a simple extension of the urban marketing process. It is a different market and presents a different set of premises on the basis of which suitable marketing.

\section{EXPLOITATION OF RURAL CONSUMERS}

With the growth in rural markets and due to poor knowledge about their rights and lack of skills to take a rational decision based on information about the product or services, the rural consumers in India are being exploited in many ways. The rural consumer has been made to endure sub-standard products and services, adulterated foods, short weights and measures, spurious and hazardous drugs, exorbitant prices, endemic shortages leading to black marketing and profiteering, unfulfilled manufacturing guarantees and host of other ills. The rural consumers who generally depend on weekly markets to purchase essential things are often cheated due to lack of choice.

The rural consumers in India are generally ignorant and they are also unorganized. Thus, they are exploited by the manufacturers, traders and the service providers in different way. The rural consumers are not only scattered but also diverse and heterogeneous. As a result of globalization and liberalization the rural market in India is the largest potential market in the world. Thus, there are vast opportunities for rural marketing. The manufacturers and traders take advantage of the condition of the rural consumers. It has been observed that the condition of the rural consumers is deplorable because they are largely exploited in the rural markets on account of lack of competition among the sellers. The rural consumers face various problems like adulteration, short weighing and measuring, lack of safety and quality control in appliances and equipment's, electrical and mechanical, unfair warranties and guarantees, imitation, sales gimmicks and unreasonable pricing.

\section{EMPOWERING RURAL CONSUMERS}

India lives in numerous villages, scattered throughout the country. Rural areas currently are home to nearly 70 percent of India's population and have historically accounted for more than half of Indian consumption. Even with increasing urbanization and migration, it is estimated that 63 percent of India's population will continue to live in rural areas by 2025 . In terms of economic output, rural India accounts for almost half (48percent) of the country's economy and the rural markets have the potential to reach $\$ 500$ billion by 2020. Thus rural areas will continue to remain vitally important to the Indian economy. However, it is an unfortunate truth that a large percentage of this population lacks even basic services like education, health, drinking water, sanitation and employment.

\section{CONCLUSION}

Like any market that has seen a demand and awareness boom, rural India has been witnessing considerable rise in purchasing power. Rural consumers are buying more health, hygiene, personal grooming and packed foods products reflecting a rise in prosperity. The expansion of mass media has further given impetus to consumerism in the rural areas. A change in consumption patterns and access to communication media has made rural market a vital $\operatorname{cog}$ in the sales-growth wheel. However, as there is no check on production and sale of such products in the rural markets, many of these products sold are of inferior quality. It is common to find that farmers are supplied defective seeds and adulterated pesticides. Rural markets and haats are full of substandard goods and duplicity of branded goods is yet another major problem. The rural consumers face various problems like fake brands and spurious products, misleading advertisements, adulteration, short weighing and measuring, lack of safety and quality control in appliances and equipments - electrical and mechanical, unfair warranties and guarantees, imitation, sales gimmicks and unreasonable pricing. It is encouraging to note that there is a remarkable improvement in buying behavior and consumption pattern of rural consumers, which will create more demand to companies in future as well. But the companies also have to accept this fact that rural buyers look for value for money from their purchase and do not buy anything for the sake of buying it. As also reported in the study that brand and price play an important role in their choice, hence the marketers should think only of rural variations of their products with desired innovations to meet the need and the context of the rural consumers, leaving the product features essentially the same as those offered to urban 


\section{Available online at www.ijrat.org}

consumers. Tapping the ocean of rural market in India demands creative marketing and many developmental efforts to be made in order to exploit the immense marketing opportunities. In the rural areas, demand has to be created and for this personal selling is supreme means of promotion because rural sales force have familiarity with rural culture, traditions and habits. The sales person has a plus point that he can communicate in the local rural languages. Further, the marketers should also use non-conventional communication media such as haats, melas, folk media, puppet shows and mobile audio-visual van having portable exhibition kit for village-to-village sales campaigns.

\section{REFERENCES}

[1] Anand, M.M. (1974), "Advertising and Sales Promotion Techniques in Rural India", Indian Management, 13(3), pp. 31-34.

[2] Aneja, R.K. (1993), "Pricing Strategies for Rural Markets", The Economic Times, September 23.

[3] Aneja, R.K. (1993), "Test Marketing of New Products in Rural Areas", Economic and Political Weekly, May 29, pp. M77-M79.
[4] Balakrishna M.D. (1975), "Rural Marketing Myth and Reality", Economic and Political weekly, August, pp M80.

[5] Ganguly, A.K. (1981), "Rural Marketing Strategy: Attempts to Explore New Areas", Sedme, Vol. III, No. 2.

[6] Garga P., Ghuman K, Dogra B. (2009), "Rural Marketing of Select Fast Moving Consumer Goods in Punjab", Indian Journal of Marketing: 39: 21-27.

[7] Gopalaswamy T.P. (1997), "Rural Marketing", Wheeler Publishing House, New Delhi.

[8] Gupta, V.K. (1972), “An Approach to Rural Marketing", Indian journal of Marketing, Vol. 2, No. 5, pp. 12-20.

[9] Nagaraja (2004), "Consumer Behavior in Rural Areas: A Micro level Study on Buying Behavior of Rural Consumers in Kaval Mandal”, Indian Journal of Marketing, 34: 30-35.

[10] Philip Kotler (2005), "Marketing Management", Prentice Hall of India, Delhi.

[11] Selvaraj A. (2007), “Rural Consumer's Behavior regarding Non-Durable Goods: A Study in Erode District of Tamil Nadu", Indian Journal of Marketing, 37: 35-39. 